\title{
Participatory Action Research with Stakeholders for Creating Value Added Innovations towards Dhamma and Merit-Making Tourism and Event Marketing of Temple Destinations in Ayutthaya Province
}

\author{
Jirusth Sirasirirusth, PhD \\ Asst. Prof. Jirawat Anuwichanont, PhD \\ Assoc. Prof. Sirivan Serirat \\ Asst. Prof. Pimmada Wichasin, PhD \\ Asst. Prof. Jiranud Sapa, PhD \\ Akanid Lertsirisrisakul \\ Naowarat Lertmaneephong \\ Suan Dusit Rajabhat University \\ 295 Nakhon Ratchasima Rd, Khwaeng Dusit \\ Dusit, 10300 \\ Bangkok, Thailand \\ Widchaporn Taipjutorus, PhD \\ Rajamangala University of Technology Phra Nakhon \\ 399 Thanon Samsen, Khwaeng Wachira Phayaban \\ Dusit, 10300 \\ Bangkok, Thailand
}

\begin{abstract}
This research was aimed to study the participatory action with stakeholders for creating value-added innovations towards Dhamma and merit-making tourism and event marketing of temple destinations in Ayutthaya province. Qualitative research along with participatory and action research were adopted for analysis. The total of 33 key informants included (1) 7 government officers (2) 10 scholars/liaisons/communities/tourists and Dhamma practitioners (3) 16 abbots. The temples in this study were categorized into 2 groups consisting of (1) Merit-making temples (Wat Yai Chaimongkol, Wat Phananchoeng, Wat Tha Ka Rong, and Wat Na Phra Men) (2) Dhamma practice temples (Wat Mahaeyong and Wat Tarn Ain). The research findings from the interviews of the mentioned key informants concerning the participatory action with stakeholders for creating value-added innovations towards Dhamma and merit-making tourism and event marketing of temple destinations in Ayutthaya province were shown as follows:
\end{abstract}

1. Activities under the cooperation among temples, the government sector, educational institutions, and communities

- Arranging Dhamma rooms by allocating the facilities of educational institutions for Dhamma practice on important religious days.

- Volunteer projects for public services such as Landscape Architectural Improvement Projects and Reforestation Program for the Father (King Rama IX).

- Merit-making projects in remembrance of His Majesty King Bhumibol Adulyadej and sustaining the projects under the patronage of His Majesty the King.

- Religious activities on religious days aiming for Dhamma practice such as watchnight service on New Year's Eve.

- Incorporating the philosophy of Sufficiency Economy with Buddhist principles for Dhamma practice.

- Developing temple websites linking with Tourism Authority of Thailand, provincial culture offices and other related organizations.

- Posting signs containing Buddhist poems and proverbs at buildings and trees in the temples.

- Developing innovative projects of Dhamma learning with songs under the cooperation with educational institutions. 


\section{Innovations for creating value-added innovations towards Dhamma and merit-making tourism and event marketing}

- Organizing Po Leaves of Merit project by cultivating the principles of wisdom, precepts and meditation for Dhamma practice. Tourists have the opportunities to write down the merit they expect to do in the future on Po leaves and tie them on the Po trees of merit. All Po leaves will be collected to cast a Buddha statue.

- Using digital innovations to provide the details of the archaeological sites such as barcodes and QR codes.

- Merit-making Rally Project at 9 temples devoted to His Majesty King Bhumibol Adulyadej by collecting merit or points which motivate tourists to participate in activities according to the rally plan.

- Using Buddhist songs to determine inhalation and exhalation pace according to the principles of Dhamma learning.

- Utilizing digital media, social media and mobile phone applications to promote Dhamma practice and temple tourism.

- Developing an augmented reality map and book to promote Dhamma practice.

- Developing innovations of Dhamma learning with e-books and multimedia books through social networks.

Keywords: Participatory Action Research (PAR) with Stakeholders, Creating, Innovation, Value Added

\section{Introduction}

Ayutthaya Province is a tourist attraction full of archeological sites, antiques, and 417 years of history (Ayutthaya Provincial Office, 2013). Moreover, it has been announced since 1991 as a world heritage site having a unique identity, customs, traditions, and civilization that still remain (Bureau of International Cooperation, Ministry of Education Thailand, 2014). There are also as many as 504 temples in Ayutthaya (Ayutthaya Provincial Office of Buddhism, 2012); therefore, temples are important attractions consisting of archeological sites, antiques, long histories as well as being attractions for Dhamma and merit-making tourism.

The characteristics of temples in Ayutthaya can be classified into two types. The first type, such as Wat Maheyong and Wat Tarn Ain, is for people who mainly visit temples to practice Dhamma and make merit. The second type, such as Wat Yai Chaimongkol, Wat Na Phra Men, Wat Phananchoeng, and Wat Tha Ka Rong, is aimed by both Thai and foreign tourists as a place to learn about history, archeological sites, and antiques of the world heritage city of Ayutthaya. However, Thai tourists also come for merit making along with travelling.

In addition, temples also organize temple fairs in various festivals with cooperation from all sectors such as entrepreneurs, the government sector, monks, liaisons/communities/Dhamma practitioners and other related groups. Therefore, it leads to the question of how different groups would collaborate to create value-added innovations for Dhamma and merit-making tourism and event marketing of temple destinations in Ayutthaya.

From the previously mentioned information, the research team see the significance of Participatory Action Research (PAR) with stakeholders which consist of temples, entrepreneurs, the government sector, monks, liaisons/communities/Dhamma practitioners and other related groups. They can all participate in PAR, which is the way to get the community involved in research and to learn from experience. Active cooperation from every person involved with the research starts with determining the problems, operation, data analysis as well as finding solutions or activity promotion (Chantavanich, 2004, p. 67). PAR in this research aims to create value-added innovations for Dhamma and merit-making tourism and event marketing of temple destinations in Ayutthaya so that the visitors are satisfied and see more value of temple tourism. Especially, the group of Dhamma practitioners would find peace in life, which is considered spiritually valuable, and they can take the experience from Dhamma practice to use in their daily life.

Therefore, innovation creation is to create initiative ideas that can respond to the needs of tourists/Dhamma practitioners by having the stakeholders search for creativity. This is considered an opportunity for Dhamma practice innovations to create spiritual value that can lead to a happier life based on Buddhist principles, which teach about suffering and cessation of suffering. That is, there are 3 ways to cease suffering as follows: (1) refraining from evil deeds, which is to refrain from behaving badly bodily, verbally, and mentally (2) cultivating virtuous deeds, which is to do good things bodily, verbally, and mentally (3) purifying the mind from sorrow, greed, anger, and delusion (Somdet Phramahasamanachao Kromphraya Vajirananavarorasa, 2017, p.5). 


\section{Literature Review}

1. Model of creative tourism following the approach of Ohridska-Olson and Ivanov (2010) is influenced from 2 factors which are:

1.1 Demand factors are defined by tourists' travelling demands as follows: (1) Participation in culture (2) Creativity (3) Innovation (4) Cultural heritage preservation (5) Authenticity (6) Human interaction (7) Cultural immersion and (8) Cultural travel and tourism.

1.2 Supply factors are capability of the service providers to present their products, consisting of (1) Creative industries (2) Global cultural diversity (3) Unique local cultural offerings (4) Hospitality (5) Local tourism infrastructure and (6) Cultural tourism resources.

2. Participatory Action Research (PAR) is the method of getting the stakeholders involved in research, which is learning from experience. Active cooperation from every person involved with the research starts with determining the problems, operation, data analysis as well as finding solutions or activity promotion (Chantavanich, 2004, p. 67). PAR consists of (1) Participation in community lifestyles (2) Action leading to experience (3) Research leading to knowledge and ideas (Chevalier \& Buckles, 2013). The process of PAR is as follows: (1) Planning, related to the question of what we want to change (2) Act, related to the question of what we are doing (3) Collect, related to the question of what data to collect (4) Reflect (Ryeder \& Wilson, 1997).

\section{Dhamma and merit-making tourism and event marketing}

3.1 Dhamma. It is human's duty to behave properly according to the natural law in every step of his evaluation in order to live happily both individually, collectively, or globally (Buddhadasa Indapanno, 2015).

3.2 Dhamma practice. There are suggestions of practices that support Dhamma practice as follows: (1) having faith in practicing insight meditation (2) having endeavor and patience towards distractions (3) refraining from talking or only when necessary (4) eliminating all worries and concerns (5) Dhamma practitioners must be unambitious, solitary, and always bear in mind that they are attempting to abandon defilements (sorrow), desire, attachment, wrong views, and pride (6) always having consciousness in all movements (7) listening to what teachers say and advise (8) continuously practicing even at home (9) keeping consciousness over all emotions (Phra Khru Palad Kittiwat, 2012, p.22).

3.3 Merit making: Punnakiriya-vatthu 3 (the three bases of meritorious action) consists of (1) Danamaya, merit acquired by giving (2) Silamaya, merit acquired by observing the precepts (3) Bhavanamaya, merit acquired by mental development (Somdet Phramahasamanachao Kromphraya Vajirananavarorasa, 2017, p. 11). These actions can be divided into sub-actions called Punnakiriya-vatthu 10 as follows: (1) giving (2) precept observation (3) mental development (Dhamma practice to understand Dhamma principles) and praying (4) being humble to seniors (5) rendering services (6) sharing merit (7) rejoicing in others' merit (8) listening to the doctrine or right teaching (9) teaching the doctrine or showing truth (10) straightening one's views or forming correct views (Phra Dharmsinghaburajarn, 2010, p.13).

Satipatthana 4 (the foundations of mindfulness) is the way of practicing to cease suffering and developing the mind to be filled with Dhamma in order to be free from reincarnation, consisting of the following: (1) Kayanupassana : this body has no beauty, thus, the elimination of satisfaction and dissatisfaction (2) Vedananupassana : having happiness and suffering as well as having no happiness nor suffering all mean suffering since happiness only conceals suffering (3) Cittanupassana : the mind is ever-changing, unsteady, and impermanent (4) Dhammanupassana : emotions occurring to the mind have causes, and when the causes cease, the emotions also cease, so nothing is tangible (Phra Dharmsinghaburajarn, 2010, p.43).

Ariyasacca 4 (the Four Noble Truths) consists of (1) Dukkha (suffering from many problems in life) (2) Samudaya (the cause of suffering) (3) Nirodha (the cessation of suffering) (4) Magga (the path leading to the cessation of suffering). Based on the Four Noble Truths, Magga is the practice to cease suffering. Buddhism demonstrates that wisdom occurs when one realizes what the causes of suffering are and how to cease that suffering. Magga can be divided into 8 aspects called the Noble Eightfold Path, which consists of the right understanding, the right thought, the right speech, the right action, the right livelihood, the right effort, the right mindfulness, and the right concentration. Therefore, Magga 8 is comparable to precepts, meditation, and wisdom (Somdet Phramahasamanachao Kromphraya Vajirananavarorasa, 2017, p.26-27). 


\section{Research Methodology}

Qualitative research along with participatory and action research were adopted for analysis. The total of 33 informants included (1) 7 government officers (2) 10 scholars/liaisons/communities/ tourists and Dhamma practitioners (3) 16 abbots.

The temples in this study were categorized into 2 groups consisting of (1) Merit-making temples (Wat Yai Chaimongkol, Wat Phananchoeng, Wat Tha Ka Rong, and Wat Na Phra Men) (2) Dhamma practice temples (Wat Mahaeyong and Wat Tarn Ain). The research findings from the interviews of the mentioned key informants concerning the participatory action with stakeholders for creating value-added innovations towards Dhamma and merit-making tourism and event marketing of temple destinations in Ayutthaya province.

\section{Research Findings and Discussion}

\section{Activities under the cooperation between temples and governmental sector, educational institution and communities}

1.1 Arranging Dhamma rooms by allocating the facilities of educational institutions for Dhamma practice on important religious days.

1.2 Volunteer projects for public services such as Landscape Architectural Improvement Projects and Reforestation Program for the Father (King Rama IX).

1.3 Merit-making projects in remembrance of His Majesty King Bhumibol Adulyadej and sustaining the projects under the patronage of His Majesty the King.

1.4 Religious activities on religious days aiming for Dhamma practice such as watchnight service on New Year's Eve.

1.5 Incorporating the philosophy of Sufficiency Economy with Buddhist principles for Dhamma practice.

1.6 Developing temple websites linking with Tourism Authority of Thailand, provincial culture offices and other related organizations.

1.7 Posting signs containing Buddhist poems and proverbs at buildings and trees in the temples.

1.8 Developing innovative projects of Dhamma learning with songs under the cooperation with educational institutions.

Discussion: activities from 1.1, 1.4, and 1.7 require collaboration among temples, educational institutions, government sector, and communities. All four parties need to rely on one another in terms of experts, venues, as well as customer acquisition, which is consistent with the idea that participation and collaborative marketing is needed (Kotler, Kartajaya \& Setiawan, 2010, pp.8). Moreover, activities in 1.2, 1.3, 1.5, 1.6, and 1.8 require collaboration among temples, educational institutions, the government sector, and communities, who need to work together and help one another in order to achieve the goals by following the steps of PAR as follows: (1) Planning, related to the question of what we want to change (2) Act, related to the question of what we are doing (3) Collect, related to the question of what data to collect (4) Reflect (Ryeder \& Wilson, 1997).

\section{Innovations for creating value-added innovation towards Dhamma and merit-making tourism and event marketing}

2.1 Organizing Po Leaves of Merit project by cultivating the principles of wisdom, precepts and meditation for Dhamma practice. Tourists have the opportunities to write down the merit they expect to do in the future on Po leaves and tie them on the Po trees of merit. All Po leaves will be collected to cast a Buddha statue.

2.2 Using digital innovations to provide the details of the archaeological sites such as barcodes and QR codes.

2.3 Merit-making Rally Project at 9 temples devoted to His Majesty King Bhumibol Adulyadej by collecting merit or points which motivate tourists to participate in activities according to the rally plan.

2.4 Using Buddhist songs to determine inhalation and exhalation pace according to the principles of Dhamma learning.

2.5 Utilizing digital media, social media and mobile phone applications to promote Dhamma practice and temple tourism.

2.6 Developing an augmented reality map and book to promote Dhamma practice.

2.7 Developing innovations of Dhamma learning with e-books and multimedia books through social networks.

Discussion: activity 2.1 Po Leaves for Merit project should lead to the learning of precepts, meditation, and wisdom. It is consistent with the theory of learning by experience, which claims that direct experience from practicing precepts, meditation, and wisdom results in learning by experience (Schiffman \& Wisenblit, 2015, p.48). Furthermore, activities $2.2,2.4,2.5,2.6$ and 2.7, related to communication via various media, follow the response process model which claims that data receivers have AIDA, consisting of attention, interest, desire, and action. It is also consistent with the 
innovation adoption model following the steps of awareness, interest, evaluation, trial, and adoption (Belch \& Belch, 201, p.159). Moreover, activity 2.4 using songs to teach Dhamma is learning by direct experience, that is, the practitioners listen to songs and sing along, resulting in understanding, easy memorization, and good feelings leading to practice (Schiffman \& Wisenblit, 2015, p.158).

Recommendations for further applications concerning the participatory action with stakeholders and creating value-added marketing innovations towards Dhamma practices and merit-making tourism and event marketing of temple destinations in Ayutthaya

Section 1: Value-added marketing innovations for Dhamma and merit-making tourism and event marketing of temples in Ayutthaya

\section{Group 1: Temples focusing on Dhamma practice (Wat Maheyong and Wat Tarn Ain)}

Wat Maheyong is a temple with unique characteristics. People who visit the temple can be divided into 2 groups which are (1) Dhamma/meditation practitioners, who are the primary target group (2) tourists wanting to visit archaeological sites, who are the secondary target group.

1. Target marketing strategy. Wat Maheyong has two target groups: (1) visitors aiming to practice Dhamma or meditate, whose motive for visiting temples is to find happiness from Dhamma practice (2) visitors aiming to visit archaeological sites.

2. Market segmentation of Wat Maheyong is divided by the following criteria,

2.1 Behavioral: (1) the Dhamma practitioners are loyal and regularly practice Dhamma as well as persuading others to come and practice with them (2) the majority of archaeological site visitors do not revisit the same place.

2.2 Psychographic/psychological: (1) the Dhamma practitioners have high need-motivation towards Dhamma practice. They aim to meditate to find solutions to their problems, to cease suffering, and/or to find peace (2) archaeological site visitors are interested in external environments, adventures, and socialization (Belch \& Belch, 2015, p.47).

2.3 Age: (1) the targeted Dhamma practitioners are mainly 25 years old and over (2) archaeological site visitors are mainly targeted at age 25 years and lower (Kotler \& Keller, 2016, p.269).

3. Target market selection uses marketing strategies that aim at 2 groups: Dhamma practitioners as the primary group and archaeological site visitors as the secondary group.

4. Positioning and brand identity through marketing strategies are as follows: (1) Dhamma practitioners want to practice Dhamma to find peace and to cease suffering, which can add to their spiritual value; thus, the product positioning is to train the mind to let go, have consciousness, have patience against defilements, greed, anger, and delusion, as well as being able to practice Dhamma anytime anywhere as shown in the left figure. (2) Tourists want to see archaeological sites; thus, the product positioning emphasizes on the sites being world heritages, historical value, and long history as shown in the right figure.

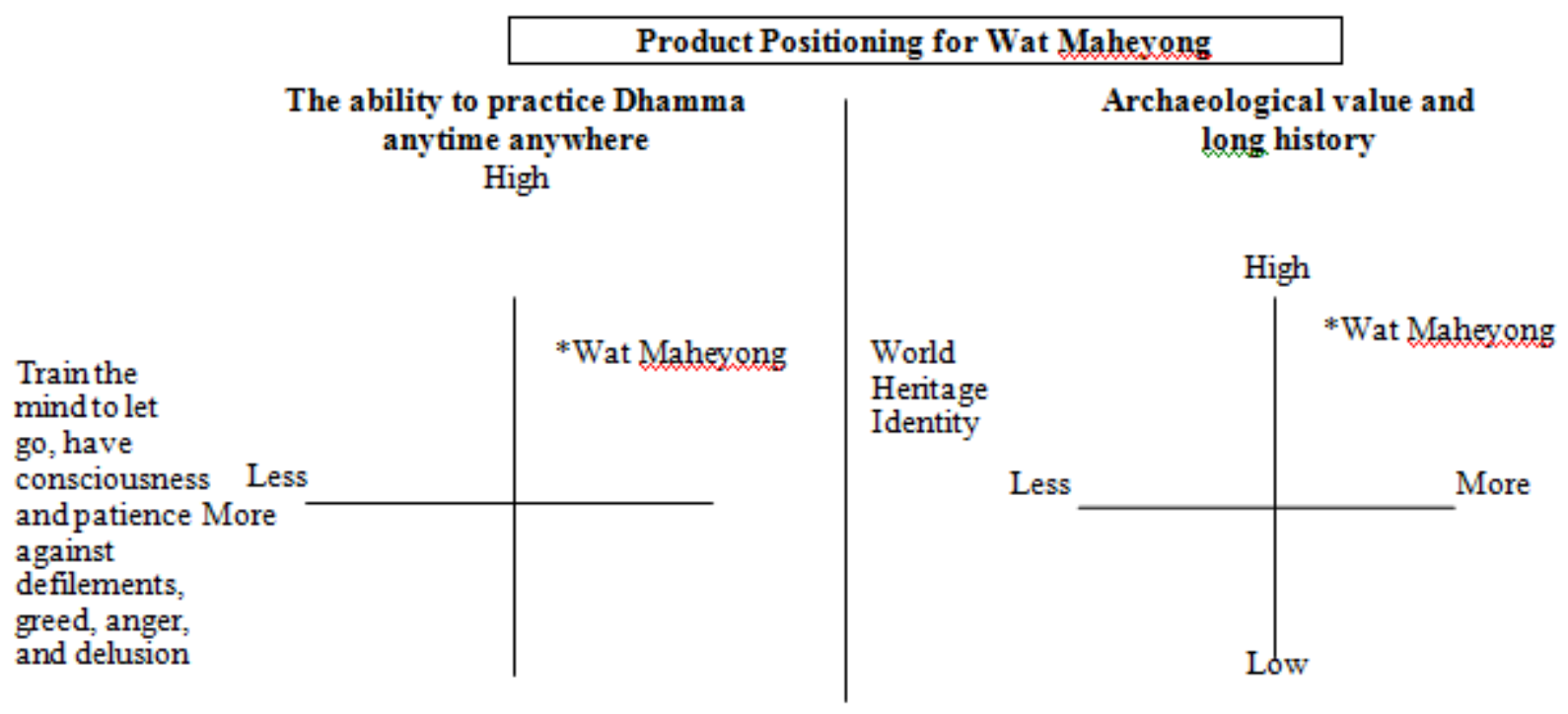

Figure 1. Product positioning for Wat Maheyong 
5. Innovation of marketing communication aims to create learning and Dhamma practice as planned in the PAR project between Wat Maheyong and the stakeholders as follows:

PAR project with Wat Maheyong is an innovation organized according to Wat
Maheyong's request
1. Temple layout consists of 2 parts (1) Dhamma practice area and archaeological area used
for Dhamma practice (2) the summary of Dhamma practice in 1 page (as attached)
1.1 two-page pamphlets with the front page showing the temple layout (A4 size) and the
back page showing Buddhist doctrines/proverbs related to Dhamma practice that can be applied in
real life (as attached)
1.2 Wat Maheyong layout on vinyl signs size 1.5 meters X 1 meters and size 2 meters X 1.5
meters
2. Print media
2.1 Small books of 4 inches width X 5.5 inches height (4"*5.5") showing mottos by Khemarangsi
Bhikku of Wat Maheyong (as attached)
2.2 Pocket books of 5.5inches width X 8inches height (5.5"*8") showing Dhamma
practice/meditation in daily life by Khemarangsi Bhikku of Wat Maheyong (as attached)
3. Dhamma learning innovations via e-book by using computers and networks linking
various websites which are interactive with the readers and augmented reality books that compile
important temples in Ayutthaya (as attached). All contents will be related to the sub-project
research and the main plan which consist of (1) Po leaves project using the principles of precepts,
meditation, and wisdom for Dhamma practice (2) Dhamma songs (3) VDO (4) proverbs and
mottos written by Khemarangsi Bhikku of Wat Maheyong.

Figure 2. Participatory Action Research (PAR) project with Wat Maheyong as an innovation requested by Wat Maheyong

Marketing communication innovation for learning can be applied by using innovations to create value-added innovations for Dhamma and merit-making tourism and event marketing as explained previously.

Wat Tarn Ain. Almost all the visitors here come to practice Dhamma. They can be divided into various programs such as short-term and moderate programs as follows:

1. Target marketing process. Most visitors at Wat Tarn Ain are Dhamma practitioners who come by themselves or with the government and private sectors to participate in the summer ordination program for monks and novices (8 days), Dhamma practice program for female youths called "Silacarini" (8 days), and the Great Path Dhamma practice program (8 days).

2. Market segmentation of Wat Tarn Ain is divided by the following criteria,

2.1 Educational level: visitors from educational institutions in the neighborhood, in Ayutthaya, and in Bangkok, who are in elementary schools, secondary schools, and higher education.

2.2 Behavioral: the group of tourists/Buddhists who have never practiced Dhamma and the group of those who regularly practice Dhamma.

2.3 Convenience and duration: the practitioners come to practice Dhamma for 1 day, 3 days, 7 days, 1 month, or in the duration according to the temple's program.

2.4 Demography based on age: male-female youths and adults, communities, the government sector, and the private sector employees.

2.5 Geography: mostly educational institutions in Ayutthaya and nearby provinces sending their children to participate in Dhamma practice.

2.6 Psychographic/psychological: the practitioners who regularly come are mostly female, whereas the number of male practitioners is small, but they have genuine intention to practice Dhamma. Moreover, the government and the private sectors recruit their employees to practice Dhamma on their own will and motivation to obtain merit from Dhamma practice.

3. Target market selection may aim at various groups depending on the duration of practice such as 1 day, 3 days, 7 days, or according to demography and/or other criteria mentioned previously. 
4. Positioning and brand identity through marketing strategies. Wat Tarn Ain mainly aims at Dhamma practice for visitors to feel peaceful and cease suffering, which is highly valuable. Therefore, the point of value added and peace from Dhamma practice can be used for positioning by claiming that they will receive greater merit than any other merit-making activities.

As for the identity of Wat Tarn Ain, the overall characteristics show that it is a rural temple surrounded by farmland. The Dhamma practice area is in an air-conditioned room, while the outdoor area has trees that are not fully grown, so the weather is rather hot. Therefore, the temple should improve its physical environment by increasing the green area with more large trees to create a peaceful atmosphere for Dhamma practice, linking the brand identity of Wat Tarn Ain to a peaceful Dhamma practice location.

5. Innovation of marketing communication is used to create learning by applying innovations to create valueadded innovations for Dhamma and merit-making tourism and event marketing as mentioned previously.

Group 2: Temples focusing on merit making consisting of 4 temples (Wat Yai Chaimongkol, Wat Phananchoeng, Wat Tha Ka Rong, and Wat Na Phra Men) apply marketing strategies as follows:

1. Market segmentation and target market selection for Thai tourists who emphasize on merit making, visiting archaeological sites, seeing antiques, and learning history in the 4 temples can be classified as follows:

1.1 Behavioral: (1) behavior of merit making (2) behavior of visiting archaeological sites, seeing antiques, learning history, as well as eating and shopping, which are considered the target marketing process (Belch \& Belch, 2015, p.47).

1.2 Age: (1) tourists aged 25 and lower as the main target group visit the temples to learn about history, archaeological sites, antiques as well as to follow their favorite historical period drama (2) tourists aged over 25 and seniors emphasize on merit making and meeting friends to recall their historical knowledge and compare it with their favorite historical period drama.

2. Target marketing strategy and market segmentation. As foreign tourists aim to visit archaeological sites, antiques, and learn history at the 4 temples in Ayutthaya which have the image of being world heritage attractions as well as this research being about Dhamma and merit-making tourism, therefore, we only focus on Thai tourists because foreigners in Ayutthaya do not have interest in merit making nor Dhamma practice.

3. Positioning and brand identity through marketing strategies. In this case, 2 types of positioning are emphasized, which are (1) showing the characteristics of Ayutthaya being a world heritage (2) motivating merit-making behavior (3) trying to create learning for merit-making visitors by adding meditation. There are options for positioning as follows: (1) the right figure emphasizes on being a world heritage and historical and archaeological value (2) the left figure emphasizes on merit making/giving/praying for good fortunes and bringing children to travel on holidays/getting together/seeing the lifestyle of people living along the river.

\section{Positioning of the temples (4 temples)}

Ment making/giving/praying for good fortunes

High

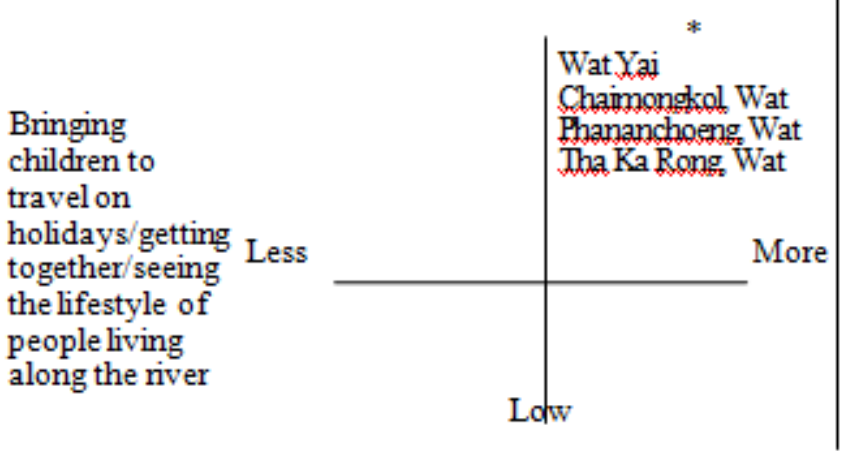

Image of being a world heritage

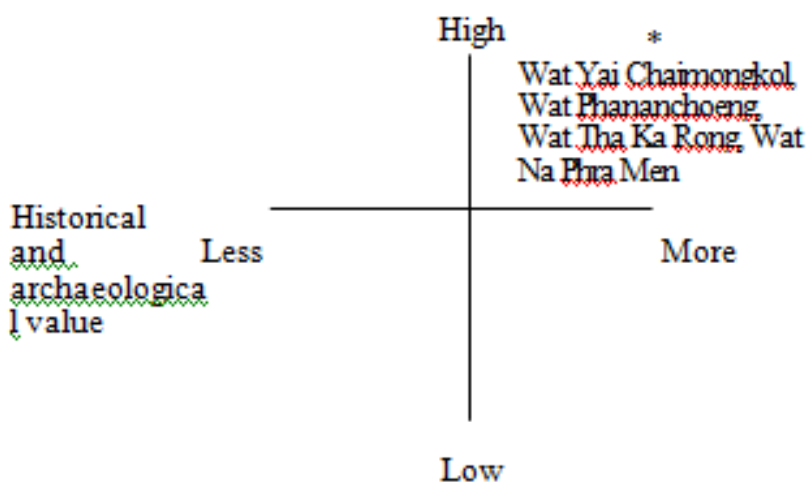

4. The communication process is related to source, message, and channel or media (Belch \& Belch, 2015, p.141). The effective method is word-of-mouth (WOM), which is an informal communication between consumers 
about products or services. These consumers are powerful sources of information. Information and media that the temples should use are as follows:

4.1 Information via print media and other traditional media as follows:

(1) Emphasize on information using communicative innovations to promote Dhamma and persuade people to practice Dhamma such as websites, applications, and QR codes by creating awareness that Dhamma practice is the greatest merit of all.

(2) Information used to persuade people into making merit must emphasize that "Time will pass, nights will pass, aging will come as a natural process. Those who see dangers in death will make merit which brings happiness" (Reverend Father Jarun Thitadhammo, Provost Samujirayuth Atichanto, 2010).

(3) Information used to persuade people to study Buddhist principles are as follows: (1) "Everything is as it is. Gaining luck comes with losing luck, gaining status comes with losing status, being praised comes with being gossiped, happiness comes with suffering" (Buddhadasa Indapanno, 1979). (2) "Tomorrow is far away, do not rush. Yesterday is gone, let it go. Do not worry about both days." (3) "If you are happy today, do not think about the future or the past. Let go of what already happened and don't worry about the dream that hasn't come true" (Reverend Father Jarun Thitadhammo, Provost Samujirayuth Atichanto, 2010).

(4) Information used to persuade people to practice Dhamma are as follows: "Compared to travelling, meditation is like walking in the sunlight without a rest area, so it's a bit hot. Those who are contented are travelling with a shaded hut they can rest at, but if they don't keep walking, they will not reach their goal" (Venerable Phavanakhemakhun Surasak Khemarangsi).

4.2 Information via the signs posted on trees in the temples emphasizes on Dhamma practice as follows: (1) "Candles are bright to the eyes. Wisdom is bright to the mind." (2) "Lighten the eyes with sunlight. Lighten the mind with Dhamma." (3) "Use problems to create wisdom." (4) "Know how to let go in order to be free." (5) "Be aware of movement of the body and be aware of perception of the mind." (6) "Stop the mind from desire." (7) "The mind is free when putting everything down and busy when holding on." (8) "Lay down...put down...to find peace." (9) "Always be conscious, don't be careless." (10) "Know how to calm the mind and know that everything is as it is." (11) "Using age to learn the truth about the body." (12) "Knowing how to have enough is enough." (13) "The shade of trees is good for resting, the shade of relatives gets rid of loneliness, the shade of parents brings happiness and alleviate suffering, the shade of Dhamma brings peace every day and night." (14) "To defeat selfishness, one shouldn't be afraid to sacrifice." (15) "Kindness is a charm. Trickiness is vicious." (16) "Using fairness to practice oneself" (Venerable Phavanakhemakhun Surasak Khemarangsi).

\section{Dhamma teaching innovations via digital media as follows:}

(1) Develop temple websites linking with Tourism Authority of Thailand, provincial culture offices and other related organizations, and use social networks such as Facebook, LINE, etc.

(2) Use the augmented reality map and book and e-book through social networks (Facebook, LINE, Instagram, Twitter) to promote Dhamma among the practitioners who self-practice Dhamma via the mentioned media, which is learning by doing.

(3) Change traditional donation boxes to automatic boxes that project voice to persuade people to donate and install Dhamma teaching program on the automatic boxes.

(4) Dhamma recreational activities/practices can be done in the forms of slow exercises such as yoga or Thai boxing dance along with music and visual media. The activities depend on the groups; for example, scout camps can include Dhamma teaching by using Dhamma songs such as the songs of Sathira Dhammasathan, Shinnakorn, G-one band, along with using cartoon drawings, photographs, and pictures of the nature.

6. Merit-making innovations aiming at visitors at the 4 temples are sequenced according to the degree of importance as follows:

6.1 Volunteer projects for environmental and cultural merit making in collaboration with educational institutions, governmental organizations, tourists, and communities by aiming at the motivation to volunteer for The Father, King Rama IX (for example, activities to continue the royal project about campaigning for Thai citizens to harmonize by using Dhamma and practice, the reforestation program devoted for King Rama IX). 
6.2 Merit-making projects by creating Sufficiency Economy system following Buddhist approaches based on sufficiency of living. Knowledge about trading can be given using Buddhist principles called Majjhima patipada or the Middle Path as well as knowledge about small businesses for the society and religion.

6.3 Adjust tour programs by including more Dhamma practice and merit making.

7. Dhamma teaching innovations to create Dhamma learning and practice based on Buddhism can be included in tour programs as follows:

7.1 Organize activities by adjusting/adding merit-seeking routes, for example, adjusting tour programs by adding Dhamma practice activities such as praying, basic meditation, which may take more or less time depending on convenience, or practicing meditation in every movement.

7.2 Develop innovative/digital/internet media to promote Dhamma and persuade people to practice Dhamma.

7.3 Manage and improve monks and temples into good role models for Dhamma practice. Moreover, each temple must improve monks/lecturers who can teach Dhamma/promote/persuade temple visitors to see the value of Dhamma practice.

7.4 Develop teaching programs or organize applied Dhamma programs for the commoners and tourists conducted by monks/lectures using Dhamma recreations such as putting in melodies for Sarabhanna or teaching meditation and prayer.

8. Dhamma practice innovations aiming to create learning of Dhamma practice can be done as follows:

8.1 Arrange Dhamma practice rooms and/or Dhamma conversation rooms/libraries using videos as concrete and valuable sources of learning for people to learn religious Dhamma practice. Moreover, interested individuals must be communicated and persuaded to practice Dhamma. Also, monks/lecturers having expertise in teaching must be available as some temples reported that they have available facilities that are not in use since there are no interested individuals coming to use the service.

8.2 Organize activities by adjusting/adding merit-seeking routes, for example, adjusting tour programs by adding Dhamma practice activities such as praying, basic meditation, which may take more or less time depending on convenience, or practicing meditation in every movement.

\section{Recommendations for Future Research}

1. Innovations for merit-making projects of various temples in Thailand

2. Innovations for Dhamma learning and practice for different levels of educational institutions by including them into tour programs

3. Dhamma recreational innovations for Dhamma learning and practice along with volunteering for environmental and cultural conservation, reinforcing the philosophy of Sufficiency Economy, and solving social problems for students in elementary schools, secondary schools and higher education

4. Digital marketing stimulation innovations to create the learning of Buddhism along with Dhamma practice for interested individuals

\section{References}

A summary report of the numbers of temples, monks, and novices in Ayutthaya Province. (2013, September 6).

Retrieved from http://aya.onab.go.th/index.php?option=com_content\&view=article\&id=175\&Itemid=123

Ayutthaya Provincial Office of Buddhism. (2012). Ayutthaya Province. (October 21, 2016), http://aya.onab.go.th/index.php?option= com_content\& view= article\&id=175\&Itemid=123

Ayutthaya Provincial Office. (2013).

Belch, G. E., \& Belch, M. A. (2015). Advertising and Promotion: An Integrated Marketing Communications Perspective. Boston: McGraw-Hill.

Buddhadasa Indapanno. (2015).

Bureau of International Cooperation, Ministry of Education Thailand. (2014)

Chantavanich. (2004). Data analysis in qualitative research.Bangkok: Chulalongkorn University.

Chevalier, J. M. \& Buckles, D. J. (2013). Participatory Action Research: Theory and Methods for Engaged Inquiry. New York : Simultaneously.

Diegmann, P., Basten, D., \& Pankratz, O. (2017). Influence of Communication on Client 
Satisfaction in Information System Projects: A Quantitative Field Study. Project Management Journal, 48(1), 8199.

How to get ultimate customer satisfaction in hospitality industry. (2015, August 27).

Retrieved from https://vietnamlabor.wordpress.com/2015/08/27/how-to-get-ultimate-customersatisfaction-in-hospitality-industry/

Kotler, P., \& Keller, K. L. (2016). Marketing management. (15th ed.). Boston, MA: Pearson Education Limited.

Kotler, P., Kartajaya, H. \& Setiawan, I. (2010). Marketing 3.0. (2nd ed). New Jersey : Prentice-Hall.

Phra Dharmsinghaburajarn. (2010). The Four Foundations of Mindfulness. Bangkok: S.P.N. Limited.

Phra Khru Palad Kittiwat. (2012). Dhamma practice Wat Tarn Ain. Bangkok: ruangviriyapattana publishing limited.

Reverend Father Jarun Thitadhammo, Provost Samujirayuth Atichanto, (2010).

Ryder, M., \& Wilson, B. (1997). From Center to Periphery: Shifting Agency in Complex Technical Learning Environments. Paper presented at the American Educational Research Association. Chicago.

Schiffman, L., \& Wisenblit, J. (2015). Consumer Behavior. Boston: Pearson Education Limited.

Somdet Phramahasamanachao Kromphraya Vajirananavarorasa, (2017).

Venerable Phavanakhemakhun Surasak Khemarangsi. (n.p., n.d.). 